\title{
Internalized Stigma among People with Mental IIIness in Serbia and the Psychometric Properties of the Ismi Scale
}

\author{
Ivona Milacic Vidojevic \\ Associate Professor, Faculty of Special Education and Rehabilitation, University of Belgrade, Faculty of Philosophy, Niksic, \\ Montenegro, Email mivona@sbb.rs \\ Nada Dragojevic \\ Associate Professor, Faculty of Special Education and Rehabilitation, University of Belgrade \\ Email dragona47@gmail.com \\ Oliver Toskovic \\ Assistant Professor, Laboratory for Experimental Psychology, Faculty of Philosophy, University of Belgrade \\ Email otoskovi@gmail.com

\section{Milica Popovic} \\ M.D. specializing in psychiatry, Special Hospital for Psychiatric Disease "Dr Laza Lazarevic" Belgrade \\ Emailmicagracilis@gmail.com
} Doi:10.5901/ajis.2014.v3n3p153

\begin{abstract}
This study was aimed at exploring the experience of internalized stigma in persons with mental illness. It also served the purpose of exploring the feasibility of using the Internalized Stigma of Mental IIIness Scale (ISMI) to establish basic psychometric characteristics. The study is a part of the international INDIGO- ASPEN project. Participants (N=103) were service users of two psychiatric clinics and one primary health service in Serbia, with severe mental illnesses (52 with diagnosis of Major depression and 51 with Schizophrenia). Participants were of different age, gender, level of education, marital and employment status. For internalized stigma assessment the ISMI scale was applied. It consists of 5 subscales and 29 questions. Participants completed a questionnaire about socio-demographic and clinical data. $17.5 \%$ of participants reported experiencing moderate or severe stigma and $82.5 \%$ mild or minimal stigma. An elevated score was established for answers at all subscales: Alienation (27.2\% of participants), Social Withdrawal (24.3\%), Stereotype Endorsement (16.5\%) and Discrimination (16.5\%). Results show that socio-demographic and clinical variables are not linked to ISMI subscales. The study results confirm the good psychometric characteristics of the ISMI. Though the experience of internalized stigma in the sample of people with depression and schizophrenia in Serbia is mildly grave it should not be discarded. Effective stigma reduction interventions should include empowerment of interpersonal relationships in persons with mental illnesses, their inclusion in selfhelp groups and self-esteem improvement.
\end{abstract}

Keywords: Internalized stigma, Mental illness, ISMI, INDIGO project

\section{Introduction}

In studies exploring the stigma of mental illness, the difference between public stigma and self-stigma has been pointed out. Public stigma refers to reactions of the general population to stigmatized group of persons with mental illnesses, while internalized stigma (also termed self-stigma) refers to prejudice which people with mental illness turn against themselves [7]. The concept of internalized stigma is of core importance in explaining the inner psychological harm done by stigma [6]. The reactions to stigma among persons who suffer from mental illnesses may differ. Some persons can be empowered with righteous anger, some remain indifferent or experience low self-efficacy and low self-esteem. Watson et al. [24] explain that stereotypes about mental illness become important when one encounters mental illness. Awareness of stereotypes alone is not enough for self-stigmatization; what is needed is that persons agree with and internalize social stereotypes [12]. People with depression assume they will be rejected socially and so believe they are not valued [13]. Internalized stigma is connected with various negative outcomes, such as aggravation of depressive symptoms, social isolation, lowered self-esteem and hope, worsening of psychiatric symptoms and decreased willingness to accept 
treatment or fail to pursue work and other important opportunities due to anticipated discrimination.

Scales exploring subjective experience of stigma and discrimination are many [22]. The ISMI scale is the most extensive and widely used in many studies $[17 ; 3 ; 11 ; 8 ; 15 ; 14 ; 5]$. The measure of internalized stigma conceptualized by Ritsher et al. [17] is based on the idea that the cause of mental illness stigma is the perception of dissimilarity and deviancy held by the general public as well as by persons with mental illnesses. In an overview of the best-validated instruments to measure internalized stigma, 21 instruments were assessed. Of all the instruments included only two were positively evaluated, ISMI and Child Attitude towards IIIness Scale [21].

Studies exploring self-stigmatization of persons with mental illnesses in Serbia are few. The ISMI and Rosenberg self-esteem scale applied to a sample of 30 persons with a diagnosis of schizophrenia suggest that internalized stigma is an important factor affecting the self- esteem in patients with a diagnosis of schizophrenia [16]. One study showed a moderate level of internalized stigma in the sample of 40 persons with schizophrenia [2]. Patients with higher levels of internalized stigma had significantly worse quality of life and lower self-esteem. There was a positive correlation between the level of depressive symptoms and the level of internalized stigma.

\section{Aim of the Study}

This study was aimed at exploring the experience of internalized stigma in persons with mental illness in Belgrade, Serbia. It also served the purpose of exploring the feasibility of using the Internalized Stigma of Mental Illness Scale (ISMI) to establish basic psychometric characteristics.

This study is a part of the international project The Anti Stigma Program: European Network (ASPEN) and the INDIGO-Depression (International Study of Discrimination and Stigma for Depression) research network. The aim of the project is to contribute to the reduction of stigma and discrimination against people with depression. ASPEN assesses the extent of stigma and discrimination against people with depression (both adolescent and adults) and gathers and disseminates information on best practices. The project is focused on the effect stigma and discrimination have in everyday lives of people with depression, and the recognition of proven strategies to reverse such forms of social exclusion.

\section{Methodology}

\subsection{Research Design and Procedure}

The study was cross-sectional survey with face- to- face interview. Data were collected in the context of the INDIGO Depression (International Study of Discrimination and Stigma Outcomes for Depression) and INDIGO Schizophrenia study. Interviews were conducted by two clinical psychologists and a physician specializing in psychiatry. The study was approved by the appropriate ethical review board at each study site. All participants provided written informed consent.

\subsection{Participants}

A sample of 103 participants with depression and with schizophrenia was assessed. The sample consisted of 51 respondents treated at the psychiatric hospital Dr. Laza Lazarević, with a diagnosis of schizophrenia, according to the Diagnostic and Statistical Manual of Mental Disorders criteria and 52 respondents treated at the Clinical Centre Dr. Dragiša Mišović Dedinje, at the psychiatric hospital Dr. Laza Lazarević and at the primary health care centre Stari grad, in Belgrade, diagnosed with a major depressive disorder, according to Diagnostic and Statistical Manual of Mental Disorders criteria. The average age of respondents was 44.2 years, and the average age of first contact with mental health services was 31.7 years. 
Table 1: Socio-demographic and some clinical data of respondents $(n=103)$

\begin{tabular}{|l|c|}
\hline & $\%$ \\
\hline Male gender & 45.6 \\
\hline University degree & 23.3 \\
\hline Employed & 26.2 \\
\hline Married & 17.5 \\
\hline Stayed at a day hospital & 58.3 \\
\hline Attended outpatient mental health care & 33.0 \\
\hline Respondents knows the diagnosis & 74.8 \\
\hline Respondents agrees with diagnosis & 63.1 \\
\hline Respondents underwent compulsory treatment & 39.8 \\
\hline
\end{tabular}

Participants completed questionnaires regarding gender, age, years, years of education, marital status, current type of treatment, age of first contact with mental health services, knowledge of diagnosis, level of agreement with diagnosis, compulsory admission .

\subsection{Instruments}

\subsubsection{Internalized Stigma of Mental IIIness Scale}

The ISMI was designed to measure the subjective experience of stigma using twenty-nine items are grouped into five subscales: Alienation, Stereotype endorsement, Perceived discrimination, Social withdrawal, and Stigma resistance. The Alienation subscale, with six items, measures the subjective experience of being a devalued member of the community. The Stereotype Endorsement subscale, with seven items, measures the degree to which respondents agree with common stereotypes about people with mental illness. The Discrimination Experience subscale, with five items, measures respondents' perceptions of the way they tend to be treated by others. The Social Withdrawal subscale, with six items, measures different aspects of social withdrawal. The Stigma Resistance Subscale, with five items, measures a person's ability to remain unaffected by internalized stigma. All items were measured on a 4-point Likert-type agreement scale $(1=$ strongly disagree to $4=$ strongly agree). Higher total scores are indicative of higher levels of internalized stigma. In the research of Ritsher et al., [17] high internal consistency $(\alpha=0.90)$ and test-retest reliability $(r=0.92)$ was reported in a sample of veteran psychiatric outpatients.

More recent studies suggested that the Resistance subscale is at odds with other subscales [14;20]. In this respect the resistance could be considered a construct separate from selfstigmatization.

We translated the scale into the Serbian language and back-translated it into English. This was done by two psychologists with a good knowledge of English who participated in the study.

\section{Results}

\subsection{Psychometric characteristic of ISMI}

According to the results of this study the reliability of ISMI is high (0.90), for the whole scale as well as for subscales, except for the resistance subscale, In table 2 the results of four studies applying ISMI are presented $[17 ; 5 ; 9]$ and Milačič Vidojević.

Table 2: Psychometric data for Internalized Stigma of Mental Illness Scale (Cronbach's Alpha)

\begin{tabular}{|l|c|c|c|c|}
\hline \multicolumn{1}{|c|}{ Subscales } & $\begin{array}{c}\mathrm{N}=127 \text { (Ritsher } \\
\text { et al., 2003) }\end{array}$ & $\begin{array}{c}\text { European version N=1229 } \\
\text { (Brohan et al., 2010) }\end{array}$ & $\begin{array}{c}\text { Iranian version N=138 } \\
\text { (Ghanean et al., 2011) }\end{array}$ & $\begin{array}{c}\text { Serbian version N =103 (Milačić } \\
\text { Vidojević et al., 2014) }\end{array}$ \\
\hline Alienation & .79 & .84 & .81 & .84 \\
\hline Stereotype endorsement & .72 & .75 & .77 & .76 \\
\hline Perceived discrimination & .75 & .79 & .80 & .77 \\
\hline Social withdrawal & .80 & .84 & .77 & .80 \\
\hline Stigma resistance & .58 & .55 & .89 & .64 \\
\hline
\end{tabular}


The results of the Kolmogorov Smirnov test showed normal distribution only for the global ISMI scores while the scores for subscales showed significant deviations. While the global scores were highly discriminative, the discriminative power of subscales was weak (see table 3). Most of the scores for Alienation, Endorsement of Stereotypes and Social Withdrawal subscales being low means that the distribution of scores for these subscales is mildly positive.

However the survey of the value for kurtosis suggest that only the subscales of Discrimination and Social withdrawal have low discriminative power (scores are grouped around the mean value). Since the kurtosis is high just for these subscales it means that their distribution is leptokurtic.

Table 3: Discriminativity of the scales and subscales - deviation from the normal distribution

\begin{tabular}{|c|c|c|c|}
\hline & & & Statistic \\
\hline \multirow[t]{4}{*}{ ISMI_alienation } & \multicolumn{2}{|l|}{ Mean } & 2.1809 \\
\hline & \multicolumn{2}{|l|}{ Std. Deviation } & .70209 \\
\hline & \multicolumn{2}{|l|}{ Skewness } & .540 \\
\hline & \multicolumn{2}{|l|}{ Kurtosis } & .124 \\
\hline \multirow[t]{4}{*}{ ISMI_endorsment } & \multicolumn{2}{|l|}{ Mean } & 2.0578 \\
\hline & \multicolumn{2}{|l|}{ Std. Deviation } & .56203 \\
\hline & \multicolumn{2}{|l|}{ Skewness } & .507 \\
\hline & \multicolumn{2}{|l|}{ Kurtosis } & .746 \\
\hline \multirow[t]{4}{*}{ ISMI_discrimination } & \multicolumn{2}{|l|}{ Mean } & 2.0568 \\
\hline & \multicolumn{2}{|l|}{ Std. Deviation } & .61381 \\
\hline & \multicolumn{2}{|l|}{ Skewness } & .441 \\
\hline & \multicolumn{2}{|l|}{ Kurtosis } & .984 \\
\hline \multirow[t]{4}{*}{ ISMI_withdrawal } & \multicolumn{2}{|l|}{ Mean } & 2.1841 \\
\hline & \multicolumn{2}{|l|}{ Std. Deviation } & .66308 \\
\hline & \multicolumn{2}{|l|}{ Skewness } & .545 \\
\hline & \multicolumn{2}{|l|}{ Kurtosis } & .146 \\
\hline \multirow[t]{6}{*}{ ISMI_total } & \multicolumn{2}{|l|}{ Mean } & 2.1655 \\
\hline & \multicolumn{2}{|l|}{ Std. Deviation } & .44829 \\
\hline & \multicolumn{2}{|l|}{ Skewness } & .308 \\
\hline & \multicolumn{2}{|l|}{ Kurtosis } & .029 \\
\hline & \multicolumn{3}{|l|}{ Kolmogorov-Smirnov } \\
\hline & Statistic & df & Sig. \\
\hline ISMI_alienation & .107 & 103 & .006 \\
\hline ISMI_endorsment & .104 & 103 & .008 \\
\hline ISMI_discrimination & .123 & 103 & .001 \\
\hline ISMI_withdrawal & .105 & 103 & .007 \\
\hline ISMI tot & .055 & 103 & .200 \\
\hline
\end{tabular}

\subsection{Prevalence of internalized stigma}

The prevalence of elevated internalized stigma was defined as an item mean score of 2.5 or higher (this criterion represented the "midpoint" on the 1 to 4 item scale). A cut off score of 2.5 was used in previous studies [18;5]. Lacking internal consistency and stronger connections to other subscales, the Resistance subscale is left out. Lysaker et al. [15], who used the Internalized Stigma of Mental IIIness Scale in a sample of people with schizophrenia in the United States, suggests that a score of 2 or less should be labeled 'minimal stigma', scores greater than 2 but less than 2.5 'mild stigma', scores greater than 2.5 but less than 3 'moderate stigma', and scores greater than 3 'severe stigma'.

For participants in this study the mean total score was 2.16 , pointing to mild self-stigmatization. Moderate and strong self-stigmatization is experienced by $17.5 \%$, and mild and minimal self-stigmatization by $82.5 \%$ of participants. Scores higher than 2.5 are obtained with $27.2 \%$ participants on the Alienation subscale, $24.3 \%$ on the Social Withdrawal subscale, $16.5 \%$ on the Endorsement of Stereotype subscale, and $16.5 \%$ on the Discrimination scale.

The experience of self-stigmatization in participants of this study is lower in comparison to results obtained for selfstigmatization experienced by participants in other European countries [5;4] and in Iran [9] (see table 4). 
Table 4: Comparison of Internalized Stigma of Mental Illness subscales in Serbia, Europe and Iran

\begin{tabular}{|c|c|c|c|c|c|c|c|c|}
\hline \multirow{2}{*}{\begin{tabular}{|l|} 
\\
ISMI subscales \\
\end{tabular}} & \multicolumn{2}{|c|}{$\begin{array}{c}\text { Serbia (Milačić-Vidojević et al., } \\
\text { 2014) N=103 (schizophrenia } \\
\text { and depression.) }\end{array}$} & \multicolumn{2}{|c|}{$\begin{array}{l}\text { Europe (Brohan et } \\
\text { al.,2010) N=1229 } \\
\text { (schizophrenia). }\end{array}$} & \multicolumn{2}{|c|}{$\begin{array}{l}\text { Europe (Brohan et al. } \\
\text { 2011) N=1182 (depression } \\
\text { and bipolar disorder) }\end{array}$} & \multicolumn{2}{|c|}{$\begin{array}{l}\text { Iran (Ghanean et al.,2011) } \\
\mathrm{N}=138 \text { (depression, bipolar } \\
\text { disorder and schizophrenia) }\end{array}$} \\
\hline & Mean & SD & Mean & $\mathrm{SD}$ & Mean & SD & Mean & $\mathrm{SD}$ \\
\hline Alienation & 2.18 & 0.70 & 2.53 & 0.70 & 2.22 & 1.09 & 2.33 & 0.73 \\
\hline $\begin{array}{l}\text { Stereotype } \\
\text { endorsement }\end{array}$ & 2.06 & 0.56 & 2.19 & 0.53 & 1.59 & 0.78 & 2.30 & 0.60 \\
\hline Discrimination & 2.06 & 0.61 & 2.43 & 0.61 & 1.91 & 0.96 & 2.32 & 0.67 \\
\hline Social withdrawal & 2.18 & 0.66 & 2.48 & 0.66 & 1.98 & 1.00 & 2.64 & 0.83 \\
\hline Stigma resistance & 2.39 & 0.59 & 2.47 & 0.51 & 2.81 & 0.98 & 2.46 & 0.39 \\
\hline \multicolumn{9}{|l|}{ Level of stigma (\%) } \\
\hline Minimal & $38.8 \%$ & & $23 \%$ & & $45.6 \%$ & & $40 \%$ & \\
\hline Mild & $43.7 \%$ & & $34 \%$ & & $30.8 \%$ & & $21 \%$ & \\
\hline Moderate & $14.6 \%$ & & 29.4 & & 18.1 & & $27 \%$ & \\
\hline Severe & $2.9 \%$ & & 12.3 & & $3.6 \%$ & & $12 \%$ & \\
\hline
\end{tabular}

Almost all differences between mean scores of internalized stigma in this study and in studies in Europe and Iran are significant, with the exception of the Resistance subscale. The experience of internalized stigma is significantly milder in participants in Serbia in comparison to participants from other parts of Europe [5] for all ISMI subscales: Alienations ( $\mathrm{t}$ 5.046 df $102 \mathrm{Sig} \mathrm{.000),} \mathrm{at} \mathrm{Stereotype} \mathrm{Acceptance} \mathrm{Subscale} \mathrm{(t-2.387} \mathrm{df102} \mathrm{Sig.019),} \mathrm{Discrimination} \mathrm{Subscale} \mathrm{(t-6.171,} \mathrm{df}$ 102 Sig .000) and Social Withdrawal Subscale ( $\mathrm{t}-4.528 \mathrm{df} 102$ Sig.000), as well as from Iran [9]: Alienations ( $\mathrm{t}-2.155 \mathrm{df}$ 102 Sig.033), at Stereotype Acceptance Subscale (t-4.374 df 102 Sig.000), Discrimination Subscale (t-4.352 df 102 Sig .000 ) and Social Withdrawal Subscale (t-6.977 df 102 Sig.000). Experience of internalized stigma was significantly milder for participants in the Brohan study [4] than for participants in Serbia for three subscales: Stereotype Acceptance (t 8.447 df102 Sig .000), Discrimination (t 2.427 df 102 Sig .017) and Social Withdrawal (t 3.125 df 102 Sig .002).

Table 5 presents the item responses. On the Alienation subscale $34.15 \%$ of the respondents agreed with all the statements, on the Social withdrawal subscale $38.1 \%$, on the Stereotype endorsment $27.9 \%$ and on the Discrimination subscale $26.5 \%$. Higher level of agreement point to the higher level of stigmatization. On the Resistance subscale $47.96 \%$ of the respondents agreeed with statements presented in the subscale which points to a higher level of stigma resistance.

Less then half of the respondents (45.6\%) agreed or strongly agreed with the Alienation subscale statement: I am disappointed in myself for having a mental illness, $37.8 \%$ of the respondents agreed or strongly agreed with the statement: I feel inferior to others who don't have mental illness, and 32\% agreed or strongly agreed with the statement I feel out of place in the world because I have mental illness.

On the Stereotype endorsment subscale 38.9\% agreed with the statement: People with mental illness cannot live a good, rewarding life, 35\% agreed with the statement: Mentally ill people shouldn't get married, and 33\% agreed with the statement: Stereotypes about the mentally ill apply to me.

Items on the Discrimination experience subscale show similar prevalnece of negative experience. $40.8 \%$ respondents agreed with the statement: Others think that I can't achieve much in life because I have a mental illness, $30.1 \%$ agreed with the statement: People often patronize me, or treat me like a child, just because I have a mental illness.

On the Social withdrawal subscale $54.4 \%$ of the respondents agreed with the statement: I don't talk about myself much because I don't want to burden others with my mental illness, $46.6 \%$ agreed with the statement: I don't socialize as much as I used to because my mental illness might make me look or behave "weird", and $38.8 \%$ agreed with the statement: Negative stereotypes about mental illness keep me isolated from the "normal" world.

Stigma resistance subscale shows that respondents express considerable empowerment. $70.9 \%$ respondents agree with the statement: I can have a good, fulfilling life, despite my mental illness, 58.3\% agreed with the statement: In general, I am able to live my life the way I want to, 43.7\% agreed with the statement: People with mental illness make important contributions to society and $33 \%$ agreed with the statement: I feel comfortable being seen in public with an obviously mentally ill person. 
Table 5: Responses to Internalized Stigma of Mental Illness Items ( $n=103)$

\begin{tabular}{|c|c|c|c|c|}
\hline & \begin{tabular}{|c|} 
Strongly disagree \\
$(\%)$ \\
\end{tabular} & $\begin{array}{c}\text { Disagree } \\
(\%)\end{array}$ & $\begin{array}{c}\text { Agree } \\
(\%)\end{array}$ & $\begin{array}{c}\text { Strongly agree } \\
(\%)\end{array}$ \\
\hline $\begin{array}{l}\text { Alienation } \\
\text { I feel out of place in the world because I have mental illness }\end{array}$ & 28.2 & 39.8 & 19.4 & 12.6 \\
\hline Having a mental illness has spoiled my life & 20.4 & 45.6 & 18.4 & 13.6 \\
\hline People without mental illness could not possibly understand me & 33.0 & 48.5 & 12.6 & 5.8 \\
\hline I am embarrassed or ashamed that I have a mental illness & 29.1 & 41.7 & 19.4 & 9.7 \\
\hline I am disappointed in myself for having a mental illness & 24.3 & 28.2 & 30.1 & 15.5 \\
\hline I feel inferior to others who don't have mental illness & 26.2 & 30.1 & 26.2 & 11.6 \\
\hline $\begin{array}{l}\text { Stereotype endorsment } \\
\text { Stereotypes about the mentally ill apply to me }\end{array}$ & 27.2 & 38.8 & 26.2 & 6.8 \\
\hline People can tell that I have a mental illness by the way I look & 35.0 & 46.6 & 13.6 & 4.9 \\
\hline Mentally ill people tend to be violent & 26.2 & 49.5 & 19.4 & 4.9 \\
\hline $\begin{array}{l}\text { Because I have a mental illness, I need others to make most decisions } \\
\text { for me }\end{array}$ & 35.9 & 45.6 & 13.6 & 4.9 \\
\hline People with mental illness cannot live a good, rewarding life & 22.3 & 38.8 & 28.2 & 10.7 \\
\hline Mentally ill people shouldn't get married & 27.2 & 35.9 & 20.4 & 14.6 \\
\hline I can't contribute anything to society because I have a mental illness & 32.0 & 43.7 & 16.5 & 7.8 \\
\hline $\begin{array}{l}\text { Discrimination experience } \\
\text { People discriminate against me because I have mental illness }\end{array}$ & 25.2 & 53.4 & 12.6 & 7.8 \\
\hline $\begin{array}{l}\text { Others think that I can't achieve much in life because I have a mental } \\
\text { illness }\end{array}$ & 24.9 & 34.0 & 27.2 & 13.6 \\
\hline $\begin{array}{l}\text { People ignore me or take me less seriously just because I have a mental } \\
\text { illness }\end{array}$ & 28.2 & 49.5 & 17.5 & 3.9 \\
\hline $\begin{array}{l}\text { People often patronize me, or treat me like a child, just because I have a } \\
\text { mental illness }\end{array}$ & 30.1 & 39.8 & 24.3 & 5.8 \\
\hline $\begin{array}{l}\text { Nobody would be interested in getting close to me because I have a } \\
\text { mental illness }\end{array}$ & 31.1 & 51.5 & 12.6 & 4.9 \\
\hline $\begin{array}{l}\text { Social withdrawal } \\
\text { I don't talk about myself much because I don't want to burden others with } \\
\text { my mental illness }\end{array}$ & 13.6 & 21.1 & 39.8 & 14.6 \\
\hline $\begin{array}{l}\text { I don't socialize as much as I used to because my mental illness might } \\
\text { make me look or behave "weird" }\end{array}$ & 28.2 & 25.2 & 34.0 & 12.6 \\
\hline $\begin{array}{l}\text { Negative stereotypes about mental illness keep me isolated from the } \\
\text { "normal" world }\end{array}$ & 28.2 & 32.0 & 29.1 & 9.7 \\
\hline $\begin{array}{l}\text { I stay away from social situations in order to protect my family or friends } \\
\text { from embarrassment }\end{array}$ & 31.1 & 42.7 & 17.5 & 8.7 \\
\hline $\begin{array}{l}\text { Being around people who don't have a mental illness makes me feel out } \\
\text { of place or inadequate }\end{array}$ & 31.1 & 38.8 & 22.3 & 6.8 \\
\hline $\begin{array}{l}\text { I avoid getting close to people who don't have a mental illness to avoid } \\
\text { rejection }\end{array}$ & 35.0 & 44.7 & 10.7 & 9.7 \\
\hline $\begin{array}{l}\text { Stigma resistance } \\
\text { I feel comfortable being seen in public with an obviously mentally ill } \\
\text { person }\end{array}$ & 18.4 & 48.5 & 22.3 & 10.7 \\
\hline In general, I am able to live my life the way I want to & 17.5 & 24.3 & 44.7 & 13.6 \\
\hline I can have a good, fulfilling life, despite my mental illness & 13.6 & 15.5 & 54.4 & 16.5 \\
\hline People with mental illness make important contributions to society & 21.4 & 31.1 & 34.0 & 9.7 \\
\hline Living with mental illness has made me a tough survivor & 31.1 & 38.8 & 18.4 & 8.7 \\
\hline
\end{tabular}

\subsection{Correlation with demographic and clinical variables}

The t- test for independent samples shows no difference between married and unmarried participants on ISMI scores, between participants with a university degree and participants with lower education, as well as between participants of other types of employment.

As for clinical variables the differences in ISMI scores between participants who did and those who did not have experiences of forced hospitalization were not significant. One-factorial analysis of variance shows that ISMI scores were 
not connected with the level of diagnosis acceptance.

Chi square testing in crosstabs established that ISMI scores were not related to socio-demographic variables when cut-off score is 2.5 . The only exception was that more participants with university degree have scores lower then 2.5 , at the Resistance subscale $(x 2=4.443$, df 1 , Sig .035) indicating that more education is associated with less stigma resistance.

\section{Discussion}

The primary purpose of this study has been to validate the psychometric characteristics of the ISMI scale in a population with mental illness in Belgrade, Serbia. The results show that the reliability of the scale in general is high $(0.90)$, and of subscales it is high or satisfactory. The Kolmogorov Smirnov test has been used to verify deviation from normal distribution and the test showed that only the total score had the optimal discrimination, while other subscales had reduced discrimination. The ISMI scale can be recommended for examination of internalized stigma in study population.

We also attempted to use the with ISMI scale to examine the internalized stigma in people with mental illness in Belgrade, Serbia. We examined 103 individuals (52 with depression and 51 with schizophrenia [17] who were on psychiatric treatment in different mental health facilities in Belgrade. In our study $17.5 \%$ of subjects experienced moderate to severe stigma, and $82.5 \%$ minimal or mild stigma. Studies conducted in Serbia on people with schizophrenia [16;2] indicate mild to moderate levels of experienced internalized stigma. A comparison of this study with research conducted in European countries and Iran shows that the experience of stigmatization of people with mental illnesses in Belgrade, Serbia is mild. Results of the Brohan [5] study suggest that self-stigmatization becomes frequent and sometimes very serious in people with schizophrenia and other psychotic disorders in Europe, where almost half (41.7\%) of the patients experienced moderate or high levels of internalized stigma. The study by Brohan [4] exploring the level of stigmatization in people with depression and bipolar disorder in 13 European countries indicates that $76.4 \%$ of respondents reported minimal and mild stigma, and in the study of Ghanean [9] in the sample of persons with depression, bipolar disorder and schizophrenia, $61 \%$ of respondents reported minimal and mild stigma and $39 \%$ moderate and severe. The level of stigmatization may vary depending on the sample included in the study, but Brohan [4] suggests that additional research is needed to examine the impact of other indicators that help us to clarify the relationship between diagnosis and self-stigmatization. Differences in scores between the findings of our study and the findings of research in Europe and Iran is significant on most of the scales. The sample from Serbia differs from the samples from the other three studies. It is considered that the development of the stigma may be conditioned by the social context so it is important to compare the concepts of internalized stigma in different countries in order to understand the processes that are at its core. The milder experience of self-stigmatization of respondents in Serbia could be explained by a lower index of individualism in Serbia and a more collectivistic centered community [10]. The fundamental issue addressed by this dimension is the degree of interdependence a society maintains among its members. Serbia, with a low score of 25 is considered a collectivistic society. This is manifest in a close long-term commitment to the member 'group', be that family, extended family, or extended relationships. The society fosters strong relationships where everyone takes responsibility for fellow members of their group. In our study respondents have the lowest scores on the Discrimination and Stereotype Endorsement subscales and the highest scores on the subscales Alienation and Social withdrawal, which is consistent with other studies $[4 ; 14 ; 17 ; 20 ; 16]$. Brohan [4] argues that the internalization of the stereotypes, which refers to the acceptance of reduced expectations or the application of stereotypes to themselves is not so common, which has implications for the concept of internalized stigma. The findings of our study confirm that the acceptance of the stereotypes is the aspect of the construct of internalized stigma which is accepted with the lowest frequency. Alienation is the most generally accepted, social withdrawal and discrimination as well. This suggests that a sense of isolation and difference can be one component of the self-stigmatization process. Social withdrawal is another mechanism through which stigma affects people with mental illness (Link et al., 1991). People with mental illness tend to avoid situations in which they anticipate to be stigmatized and discriminated against, which largely leads to passivity of people with mental illness in social relations and realization of personal needs. In the research of self-stigmatization and factors associated with it in the population of persons with depressive disorder, Yen et al., (2005) results show that the higher selfstigmatization is associated with the severity of depression and lower levels of education. Gender, age, duration of illness, knowledge about depression, contact with the person with depression and social status were not associated with self-stigmatization. Self-stigmatization in bipolar patients was observed more frequently in patients with low socioeconomic status, low level of education, rural residence, lack of work, and more children [23]. A higher rate of internalized stigmatization at lower education level has so far been demonstrated in other mental diseases, which is consistent with the literature [1]. Employment, education, and a high socioeconomic level appear to be factors that 
decrease the incidence of internalized stigmatization, which might be because they increase self-esteem. In our study the t- test for independent samples demonstrates there was no difference in the subscales according to socio-demographic variables. Only the subscale for Resistance shows correlation with education, such that the people who have a graduate degree have a score lower than 2.5 .

\section{Limitations of the Study}

The sample was obtained in two psychiatric facilities and a health care center in Belgrade, and the question is to what extent this sample is representative for the population of persons with mental illness in Serbia. A notable limitation of the current analyses is that we did not collect data on symptom severity, and therefore are unable to examine the relationship between these important variables and the likelihood of elevated internalized stigma. Also, we cannot rule out that some of the respondents, apart from their main illnesses, had other psychiatric or somatic health problems that could contribute to their perception of being stigmatized.

\section{Conclusion}

The ISMI has good psychometric properties and is a good instrument to measure internalized stigma in our sample. All ISMI scales have adequate internal consistency, except Resistance scale (alpha 0.59) which points to the need to continue working on the development of the independent Resistance scale [20]. The experience of the internalized stigma in psychiatric patients in Serbia is mild, but it should be taken seriously. Empowering people with mental illness and their organizations is important, as well as raising awareness of the stigma in professional groups working with people with mental illness.

Pointing to discrimination against people with mental illness is often used as an intervention to combat internalized stigma. However, the survey results suggest that the experience of the discrimination do not have to be strong and that is probably necessary to reduce the experience of social withdrawal and alienation by empowerment of people with mental illness, interpersonal engagement and increasing self esteem.

Although there is strong evidence of internalized stigma, the mechanisms of its formation and operation is still not determined. It is unclear whether it operates on an automatic, implicit level, beyond awareness and control, being important for the design of the anti-stigma campaign. Perhaps the experience of internalized stigma is broader and it could not be always directly determined. For that reason projective or semi projective techniques for internalized stigma assessment could be constructed.

\section{References}

Alonso, J., Buron, A., Rojas-Farreras S, et al.(2009). Perceived stigma among individuals with common mental disorders. Journal of Aff ective Disorders, 118, 180-86.

Batinic,B., Lemonis,E., Opacic,G. (2013). Effects of internalized stigma of mental disorder on quality of life and self esteem in schizophrenic patients. European Psychiatry, Vol. 28, Suppl 1 p.1

Botha, U. A., Koen, L., \& Niehaus, D. J. (2006). Perceptions of a South African schizophrenia population with regards to community attitudes towards their illness. Social Psychiatry and Psychiatric Epidemiology, Aug; 41(8), 619-623.

Brohan E., Gauci, D., Sartorius, N., Thornicroft, G. (2011). Self stigma, empowerment and perceived discrimination among people with bipolar disorder or depression in 13 European countries:The GAMIAN-Europe study. Journal of Affective Disorders 129, 56-63.

Brohan, E., Elgie, A., Sartorius, N., Thornicraft, G., \& GAMIAN-Europe Study Group. (2010). Self-stigma, empowerment and perceived discrimination among people with schizophrenia in 14 European countries: The GAMIAN-Europe study. Schizophrenia Research, 122(1-3), 232-238.

Corrigan, P.W. (1998). The impact of stigma on severe mental illness. Cognitive and Behavioral Practice 5, 201-222.

Corrigan, P.W., Watson,A. (2002). Undestanding the impact of stigma on people with mental illness. World Psychiatry,1 (1),16-20.

Ersoy, M. A., \& Varan, A. (2007). Reliability and validity of the Turkish version of the internalized stigma of mental illness scale. Turkish Journal of Psychiatry, 18(2), 163-171.

Ghanean, H., Nojomi,M., Jacobson,L. (2011). Internalized stigma of mental illness in Tehran, Iran. Stigma Research and Action, Vol 1, No $1,11-17$.

Hofstede,G., McCrae,R. (2004). Personality and Culture Revisited: Linking traits and dimensions of culture, Cross Cultural Research, Vol $28, n$ 1, 52-88.

Hwang, T. Y., Lee, W. K., Han, E. S., \& Kwon, E. J. (2006). A study on the reliability and validity of the Korean version of Internalized Stigma of Mental Illness Scale (K-ISMI). Journal of the Korean Neuropsychiatric Association, 45, 418-426.

Link, BG., Mirotznik, J., Cullen, FT. (1991). The effectiveness of stigma coping orientations: can negative consequences of mental illness 
labeling be avoided? Journal of Health and Social Behavior, 32,(3),302-20.

Link, B.G., Phelan, J.C. (2001). Conceptualizing stigma. Annual Review of Sociology, 27,363-385.

Livingston, J. D., \& Boyd, J. E. (2010). Correlates and consequences of internalized stigma for people living with mental illness: A systematic review and meta-analysis. Social Science \& Medicine, 71, 2150-2161.

Lysaker, P. H., Buck, K. D., Taylor, A. C., \& Roe, D. (2008). Associations of meta-cognition and internalized stigma with quantitative assessments of self-experience in narratives of schizophrenia. Psychiatry Research, 157(1-3), 31-38.

Lysaker, P. H., Roe, D., \& Yanos, P. T. (2007). Toward understanding the insight paradox: Internalized stigma moderates the association between insight and social functioning, hope and self-esteem among people with schizophrenia spectrum disorders. Schizophrenia Bulletin, 33, 192-199.

Nikolic-Popovic,J., Manojlovic,S.(2012). Insight and self esteem in patients with schizophrenia. European Psychiatry, Vol. 27, Suppl 1, p.1

Ritsher, J. B., \& Phelan, J. C. (2003). Internalized stigma predicts erosion of morale among psychiatric outpatients. Psychiatry Research, 129(3), 257-265

Ritsher, J. B., \& Phelan, J. C. (2004). Internalized stigma predicts erosion or morale among psychiatric outpatients. Psychiatric Research, 129(3), 257-265.

Ritsher, J. B., Otilingam, P. G., \& Grajales, M. (2003). Internalized stigma of mental illness: Psychometric properties of a new measure. Psychiatry Research, 121(1), 31-49.

Sibitz, I., Unger, A., Woppmann, A., Zidek, T., Amering, M., (2011). Stigma resistance in patients with schizophrenia. Schizophrenia Bulletin, 37 (2),316-323.

Stevelink, S. A. M., Van Brakel, W. H., \& Augustine, V. (2011). Stigma and social participation in Southern India: Differences and commonalities among persons affected by leprosy and persons living with HIVIAIDS. Psychology, Health and Medicine, 16, 695707.

Stuart, H., Koller, M., \& Milev, R. (2008). Inventories to measure the scope and impact of stigma experiences from the perspective of those who are stigmatized-consumer and family. In J. Arboleda-Florez, \& N. Sartorius (Eds.), Understanding the stigma of mental illness (pp. 193-204).London: John Wiley \& Sons Ltd.

Ustundog, M.,Kesebir,S. (2013). Internalized stigmatization in bipolar patients: relationship with clinical properties, quality of life and treatment compliance. Turkish Journal of Psychiatry,24(4), 231-239.

Watson, A. C., Corrigan, P., Larson, J. E., \& Sells, M. (2007). Self-stigma in people with mental illness. Schizophrenia Bulletin, 33, 13121318.

Yen, CF., Chen,CC., Lee, Y., Tang.TC.,Yen, JY.,Ko,CH. (2005).Self-stigma and its correlates among outpatients with depressive disorders. Psychiatric Services,56(5),599-601.

\section{Staff at INDIGO Partner Centres}

Australia: Nicholas Glozier, Nicole Cockayne (Brain and Mind Research Institute, Sydney Medical School, University of Sydney, Sydney, NSW, Australia);

Brazil: Luis Fernando Tofoli, Maria Suely Alves Costa (Universidade Federal do Ceara, Campus Sobral, Brazil);

Canada: Roumen Milev, Teresa Garrah, Liane Tackaberry, Heather Stuart (Department of Psychiatry, Queen's University, and Providence Care, Mental Health Services, Kingston, ON, Canada);

Croatia: Branka Aukst Margetic, Petra Folnegovic Grošić, Miro Jakovljević (Department of Psychiatry, University Hospital Centre Zagreb, Croatia);

Barbora Wenigova, Šelepova Pavla (Centre for Mental Health Care Development, Prague, Czech Republic);

Egypt: Doaa Nader Radwan (Institute of Psychiatry, Ain Shams University, Cairo, Egypt);

India: Pradeep Johnson, Ramakrishna Goud, Nandesh (St John’ s Medical College Hospital, St John’ s National Academy of Health Sciences, Bangalore, India) and Geetha Jayaram (Department of Psychiatry, Johns Hopkins University, USA);

Japan: Shuntaro Ando, (Department of Psychiatry and Behavioral Science, Tokyo Metropolitan Institute of Medical Science, Tokyo, Japan) and Yuriko Suzuki, Tsuyoshi Akiyama, Asami Matsunaga, Peter Bernick (NTT Kanto Hospital, Tokyo, Japan);

Nigeria: Bawo James (Federal Neuropsychiatric Hospital, Uselu, Benin City, Nigeria);

Nigeria: Bolanle Ola, Olugbenga Owoeye (Federal Neuropsychiatric Hospital Yaba, Lagos, Nigeria);

Nigeria: Yewande Oshodi (Department of Psychiatry, College of Medicine University of Lagos and Lagos University Teaching Hospital, Lagos, Nigeria);

Nigeria: Jibril Abdulmalik (Federal Neuropsychiatric Hospital, Maiduguri, Nigeria);

Malaysia: Kok-Yoon Chee, Norhayati Ali (Kuala Lumpur Hospital and Selayang Hospital, Malaysia);

Morocco: Nadia Kadri, Dounia Belghazi, Yassine Anwar (Ibn Rushd University Psychiatric Centre, Casablanca, Morocco);

Pakistan: Nashi Khan, Rukhsana Kausar (University of the Punjab, Department of Applied Psychology and Centre for Clinical Psychology, Lahore, Pakistan);

Serbia: Ivona Milacic Vidojevic (Faculty for Special Education and Rehabilitation, Belgrade, Serbia);

Sri Lanka: Athula Sumathipala, Chesmal Siriwardhana (Institute of Psychiatry, King's College London and Institute for Research and Development, Sri Lanka);

Switserland: Norman Sartorius (Association for the Improvement of Mental Health Programmes, Geneva, Switzerland); 
Taiwan: Chih-Cheng Chang (Chi Mei Medical Centre, Department of Psychiatry, Tainan, Taiwan);

Tunisia: Fethi Nacef, Uta Ouali, Hayet Ouertani, Rabaa Jomli, Abdelhafi dh Ouertani, Khadija Kaaniche (Razi Hospital Manouba, Department of Psychiatry, Tunis, Tunisia);

Venezuela: Ricardo Bello, Manuel Ortega, Arturo Melone, Maria Andreina Marques, Francisco Marco, Arturo Rios, Ernesto Rodriguez, Arianna Laguado (Hospital Universitario de Caracas, Caracas, Venezuela). 